\title{
Autonomy and Aesthetic Engagement
}

\author{
C. Thi Nguyen
}

This is a pre-proofed draft. Please cite the final version, published in Mind: https://doi.org/10.1093/mind/fzz054.

A downloadable audio recording of this paper is available at:

https://soundcloud.com/thi-nguyen-178642577/autonomy-and-aesthetic-engagement-c-thi-nguyen

There seems to be a deep tension between two aspects of aesthetic appreciation. On the one hand, we care about getting things right. Our attempts at aesthetic judgments aim at correctness. On the other hand, we demand autonomy in aesthetic appreciation. We want appreciators to arrive at their aesthetic judgments through their own cognitive efforts, rather than deferring to experts. These two demands seem to be in tension; after all, if we want to get the right judgments, we should defer to the judgments of experts. How can we resolve this tension? The best explanation, I suggest, is that aesthetic appreciation is something like a game. When we play a game, we try to win. But often, winning isn't the point; playing is. Aesthetic appreciation involves the same flipped motivational structure: we aim at the goal of correctness, but having correct judgments isn't the point. The point is the engaged process of interpreting, investigating, and exploring the aesthetic object. Deferring to aesthetic testimony, then, makes the same mistake as looking up the answer to a puzzle, rather than solving it for oneself. The shortcut defeats the whole point. This suggests a new account of aesthetic value: the engagement account. The primary value of the activity of aesthetic appreciation lies in the process of trying to generate correct judgments, and not in having correct judgments.

There seems to be a deep tension between two aspects of our practice of aesthetic appreciation. First, the practice of aesthetic appreciation seems deeply cognitive. We seem guided by an interest in getting things right. We not only look at art; we investigate it. We form trial judgments and then go back for more, re-watching and re-reading to make sure we've caught all the details. We talk about the reasons for our judgments, point out details to one another, and argue about what's truly great. The way we go about aesthetic conversation and aesthetic investigation seems to indicate that our aesthetic judgments are aimed at 
the truth.

At the same time, we seem committed to principles of individuality and autonomy in aesthetic appreciation. For one, we seem to think that, in aesthetic appreciation, we must form our own judgments for ourselves. There is a striking disanalogy here between the aesthetic and empirical realms. In empirical matters, we are often willing to defer to the judgments of others, especially when they are experts. For example, I trust my doctor and take whatever pills she tells me to take. But in aesthetic matters, we do not seem so willing to defer. There seems to be something quite problematic about acquiring the aesthetic judgment that Thelonious Monk's solo rendition of 'Smoke Gets in Your Eyes' is brilliantly complex, strictly from the testimony of a jazz expert.

This asymmetry has struck some as quite meaningful. Consider a parallel asymmetry in the moral realm. Sarah McGrath argues that our unwillingness to defer to moral experts presents a significant challenge to moral realism. Suppose I was simply aiming to have correct moral beliefs. In that case, when I had good reason to think that some other person was more reliable than me on some moral issue, then I ought to defer. However, such moral deference strikes us as deeply wrong. It can start to seem, then, as if we weren't really aiming at correctness at all. The best explanation of this asymmetry, some suggest, is moral expressivism — the view that our moral judgments express our own individual commitments or subjective responses, rather than asserting objective truths (McGrath 2011). Notice that these arguments apply just as well to the aesthetic realm. Perhaps, then, our commitment to aesthetic autonomy reveals that aesthetic judgments are simply expressions of our own responses, rather than assertions aimed at capturing objective truths.

These two strands pull us in different directions. The cognitive aspects of aesthetic life 
suggest that aesthetic claims are largely objective; our demand for autonomy suggests that they are largely subjective. This seems puzzling. As Kant put it, if aesthetic judgments are grounded primarily in our own felt responses, then what basis could we have for demanding agreement? One standard response is to commit to some form of subjectivism about aesthetic judgment, and then to offer an alternative explanation for all that seemingly cognitive behavior of arguing, discussing, and investigating. This is, perhaps, Kant's path. Cain Todd has offered such an approach in his modernized take on Kant. ${ }^{1}$ Says Todd, aesthetic judgments express our own attitudes, rather than asserting truths. But we have social reasons to express these attitudes as if we were asserting truths - for example, we might be trying to demand agreement, or urging others to share our responses. Approaches like this treat the demand for autonomy as weighing decisively in favor of subjectivism, and then attempt to provide an accommodating explanation for our apparently cognitive behavior.

I will attempt to resolve the tension between autonomy and cognitivity in the opposite direction. I will suggest that aesthetic judgments are cognitive, and then offer an accommodating explanation for our requirement for autonomy. In my account, aesthetic judgments can be straightforwardly correct or incorrect, but the reason we seek correct judgment in aesthetic appreciation differs from ordinary empirical life. In much of practical empirical life, we value having the correct judgments themselves. We engage in the activity of inquiry for the sake of its products. In aesthetic appreciation, on the other hand, we value the activity of forming judgments more than we do getting our judgments right. In this way, the practice of

\footnotetext{
${ }^{1}$ This expressivist, quasi-realist reading of Kant was originally proposed, and then dismissed, by Robert Hopkins (Hopkins 2001). Todd's article is an attempt to resuscitate Hopkins's proposal (Todd 2004). I will, for the most part, avoid coming down too firmly on the relationship between my views and Kant's, because relevant aspects of Kant's view here are still being debated (Ginsborg 2015; Gorodeisky and Marcus 2018).
} 
aesthetic appreciation has a motivational structure similar to that of playing a game. In much of game-play, we aim at winning, but winning isn't the point: playing is. In much of our aesthetic lives, we aim at correct aesthetic judgments, but actually having them isn't the point. The process of seeking them is. Our dedication to aesthetic autonomy reveals that we value aesthetic engagement over aesthetic conclusions.

\section{Autonomy and Acquaintance}

The importance of aesthetic autonomy, however, has been masked in recent conversation by the dominance of a distinct consideration — that of aesthetic acquaintance. The first task, then, is to distinguish between these two very different demands.

The demand for aesthetic acquaintance is the demand that one's aesthetic judgment of an object proceed from one's direct experience of that object. The demand for aesthetic autonomy, on the other hand, is the demand that one come to one's aesthetic conclusions through one's own efforts. Aesthetic acquaintance asks that we experience the thing for ourselves, while aesthetic autonomy asks that we draw our conclusions for ourselves. And it is the demand for aesthetic autonomy, I think, that will prove key in understanding the value of aesthetic engagement. But the demands for autonomy and acquaintance have sometimes been confused. And when they are distinguished, more attention has usually been paid to the demand for acquaintance. So let's start by getting clearer on these two demands.

The demand for autonomy concerns the degree to which aesthetic judgments arise through our own efforts. We can state that demand in the form of a principle: 
Autonomy Principle: One ought to arrive at one's aesthetic judgments through the application of one's own faculties and abilities.

According to this principle, one ought to do one's own aesthetic thinking, investigating, interpreting, and the like. One should not outsource aesthetic judgments to, say, the experts, even if they are known to be more reliable. I mean 'aesthetic judgments' here in a broad sense, including both judgments about the presence of a particular aesthetic property in an object, like sensuousness or delicacy, as well as overall evaluative judgments. One should decide for oneself whether Jackson Pollock is empty or profound, whether Thelonious Monk is full of bizarre angles or full of sensuous textures. ${ }^{2}$

The second principle is one of acquaintance, which posits a demand for direct experience:

Acquaintance Principle: One ought to arrive at an aesthetic judgment on the basis of one's own direct experience of the object of judgment. ${ }^{3}$

According to this principle, we need to have actually heard John Coltrane's Africa/Brass

\footnotetext{
${ }^{2}$ One substantial question about this presentation of the autonomy principle is what to do about cases when we act on aesthetic recommendations. Many solutions have been suggested. Hopkins's solution is to suggest that the norm of autonomy lapses because of an application of 'ought implies can' - before you have seen a work, you cannot actually judge it for yourself, so you cannot be required to (Hopkins 2011). Aaron Meskin suggests that recommendations only give us information about the likelihood of our rendering an aesthetic judgment (Meskin 2007). Elsewhere, I have argued that that recommendations pass information about aesthetic merit (Nguyen 2017). The argument of this paper is compatible with all of these approaches.

${ }^{3}$ This expression of the acquaintance principle is intended to be suitably minimal so as to be compatible with a wide swath of the literature on testimony and acquaintance, and to avoid commitment to any of the disputed details about the best articulation of the principle (Budd 2003; Livingston 2003; Meskin 2004, 2007; Laetz 2008; Hopkins 2011; Konigsberg 2012; Whiting 2015; Lord 2016; McKinnon 2017; Ransom 2019).
} 
for ourselves or tasted those lengua tacos for ourselves in order to render an aesthetic judgment. ${ }^{4}$ The Acquaintance Principle makes demands about our getting the direct aesthetic input for ourselves, while the Autonomy Principle makes demands about coming to conclusions for ourselves. ${ }^{5}$

These two principles often rear their heads in the discussion of the legitimacy of acquiring aesthetic beliefs via testimony. We seem to have the intuition that we should not acquire aesthetic judgments from bare testimonial reports. This intuition is often taken to support the so-called 'pessimistic' view of aesthetic testimony — that we cannot gain aesthetic belief through testimony (Hopkins 2011, p. 139). ${ }^{6}$ Notice that both the Autonomy Principle and the Acquaintance Principle have the resources to explain this intuition. In acquiring an aesthetic judgment from bare testimony, I have both failed to go through the cognitive processes for myself and failed to directly experience the object of my judgment for myself.

The discussion of aesthetic testimony often treats the two principles as competing explanations for the same set of intuitions, and then proceeds to try to figure out which principle offers the better explanation. For example, Hopkins considers the following argument in favor of the Acquaintance Principle over the Autonomy Principle. The Autonomy Principle, he

${ }^{4}$ There are, of course, all sorts of boundary cases involving, say, arriving at an aesthetic judgment of a painting after imagining it based in a rich description. I will set those boundary cases aside for the sake of the present discussion, and concentrate on the clearest cases of violations of the Acquaintance Principle.

${ }^{5}$ I adapt these expressions of these principles, and this approximate division of the space, from Robert Hopkins's discussion of aesthetic testimony (Hopkins 2011).

${ }^{6}$ As Madeleine Ransom notes, this intuition is fairly specific. Specifically, the intuitions seem to forbid acquiring an aesthetic judgment from 'bare testimony', in which I acquire an aesthetic judgment that $p$ based on the testimony that $p$. This is contrasted with acquiring an aesthetic judgment from 'rich testimony', where I render an aesthetic judgment that $p$ based on testimony as to particular, richly described details (Ransom 2019). Also, the standard account of the pessimistic intuition has been sometimes challenged; for example, Jon Robson has argued that the pessimistic intuitions are only about norms of asserting based on aesthetic testimony, rather than on norms of belief about testimony (Robson 2015). I will presume for this paper the standard version of the pessimistic account, which includes a norm against acquiring a belief through testimony. 
says, licenses too much. It would license acquiring aesthetic judgments through inductive reasoning, so long as that reasoning was performed autonomously. Suppose I have seen fifty pieces of abstract expressionism and find them all pleasingly textured and rich. I have not yet seen Rothko's No. 61 (Rust and Blue), but I form the aesthetic judgment that it, too, is pleasingly textured and rich, based on induction from my observations of other pieces of abstract expressionism. Notice that the cognitive processes involved are all my own. Still, this seems wrong way to go about making aesthetic judgments. The Autonomy Principle, says Hopkins, cannot account for what's wrong with inductive judgments (p. 151-2). Only the Acquaintance Principle can. It says that should actually experience No. 61 itself before I render any aesthetic judgment of that work; reasoning from induction violates that requirement. For reasons like these, the conversation about deference and aesthetic testimony has largely come to revolve around the Acquaintance Principle.

\section{The case for autonomy}

The Acquaintance Principle certainly explains what is wrong with making aesthetic judgments from induction in a way that the Autonomy Principle cannot. But the Acquaintance Principle, by itself, cannot explain other parts of the story.

Consider the following case:

\section{Audio Tour}

Brandon considers himself to be an art-lover. Whenever he goes to a museum, he rents the audio tour and explores the museum at its direction. He looks at the paintings he is told to look at, studies those details which are called to his attention, and 
always assents to the audio tour's judgment of the quality, importance, and aesthetic properties present based on those details. He never looks for any details that aren't specified by the audio tour, nor does he ever form aesthetic judgments without the explicit guidance and suggestion of an audio tour. But he does make sure to look at each specified painting, and to find and note any specified detail, before allowing himself to accept the suggested judgment. And he only accepts the suggested judgment when he sees the relevant aesthetic properties for himself, after permitting his attention to be entirely directed by the audio tour. Furthermore, he conducts his entire aesthetic life in this manner. He does not use the audio tours as a jumping off point for future exploration, but always seeks expert guidance to direct his engagement with any artwork he encounters. He never attempts to establish his own views when such guidance is unavailable.

Brandon's life is missing something important. It might be perfectly fine to begin one's aesthetic education with audio tours, or to use them as a jumping-off point for further reflection. But Brandon's use of audio tours isn't just a step along the way; it is the totality and endpoint of his aesthetic activity. His aesthetic life seems not to be fully realized. He lacks independence, we want to say; he does not fully engage with artworks in the right way. But notice that only the Autonomy Principle can explain what's missing from Brandon's aesthetic life. He is certainly acquainted with the aesthetic properties, and his judgments are formed from direct experience of an aesthetic object and its relevant aesthetic qualities. What's wrong with Brandon's conduct is not a lack of acquaintance; it is that he is aesthetically subservient. He is failing to reach the conclusions through the application of his own faculties and resources. He is letting another direct his attention, suggest interpretations, and suggest conclusions. Though he is certainly engaging some of his capacities, such as the ones re- 
quired to see details and to grasp interpretations, he is not engaging his higher-order capacities for aesthetic agency. He isn't choosing which details to attend to. He isn't forming his own interpretations or using them to guide his attention and investigation. He is not entirely lacking in aesthetic autonomy, but he is missing a substantial part of it.

The Autonomy Principle by itself cannot explain what's wrong with induction, and the Acquaintance Principle by itself cannot explain what's wrong with Audio Tour Brandon. The best account, then, is not that these two principles are competing explanations of the same phenomenon, but that they are both normatively active. Each principle articulates a different demand bearing on our aesthetic judgment.

It will be useful here to compare Audio Tour Brandon with something of an opposite case:

\section{Independent and Inductive}

Kate watches a lot of movies, and forms strong, personal, carefully thought-out reactions to all of them. After she has seen enough movies from a director or production group, she will sometimes begin to also form some inductive judgments. She states these judgments without qualification. For example, she will say that Quentin Tarantino's Hateful Eight is clever, perverse, and postmodern without having seen it herself, based entirely on induction from previous experiences with Quentin Tarantino movies. She will also say that Justice League is boring, corporate, ponderous and generally worthless, without having seen it for herself, based on induction from previous experiences with Warner Brothers versions of DC comic book properties.

What would we say about Audio Tour Brandon and Inductive Kate? Notice that we might challenge particular claims of Kate's. I would not accept her particular judgment that Justice League was boring or that Hateful Eight was clever precisely because she lacks direct acquaintance. However, I would also think that, in general, her aesthetic life was going quite 
well, though I would complain that some of her particular expressions of aesthetic judgments were misleading or unfounded. My reaction to Audio Tour Brandon is the reverse. I would accept particular aesthetic judgments of his - say, that Van Gogh's Irises displayed a bold and impactful use of line, which reveals a subtle influence from Hokusai. I might, admittedly, accept those aesthetic judgments with a bit of an eye-roll, but I wouldn't throw them out altogether. I trust Brandon to be a good conveyance of reliable aesthetic judgment, at least enough to allow his expressed judgments to direct my action and attention. ${ }^{7}$ However, I also think that Audio Tour Brandon is living a much more impoverished aesthetic life than Kate. If I were Brandon's friend, I would push him to make more judgments for himself, to let his attention roam at his own direction - to not only feel for himself, but to discover for himself the aesthetic intricacies of these artworks. If he said that he was afraid of getting something wrong, I would reply that getting all your facts in a row wasn't the end-all and be-all of aesthetic life. Inductive Kate, on the other hand, seems to be leading a rich and fulfilling aesthetic life, albeit one plagued by the occasional bizarre overreach. I might urge Kate to temper the exact wording of her claims, but not to change the basic contour of her aesthetic life. Audio Tour Brandon, on the other hand, is fully entitled to the particular content of each of his claims, but he seems to be missing out on something rather more galactic.

I have suggested that the Autonomy Principle can help to explain the asymmetry between aesthetic and empirical testimony. But, one might worry, the Autonomy Principle can't do

\footnotetext{
${ }^{7}$ I am here, I admit, making claims about what counts as aesthetic judgments, without offering an account of what it is to be aesthetic. I am following here the strategy suggested by Dominic Lopes - that we try avoiding, for the moment, getting caught up in defining the boundary of the aesthetic, and see how far we can get. I am instead taking here, as an identifying principle loosely adapted from Lopes, that a marker of a real aesthetic judgment is that it is a good basis for further aesthetic actions (Lopes 2018, p. 46-8).
} 
that explanatory work because it is, in fact, a general requirement for all agents in all domains. After all, shouldn't we always think for ourselves, directing our own attention and coming up with our own theories about the world? How could a general principle of agency account for the asymmetry between the aesthetic and the empirical?

As a matter of fact, I do not think that we demand the same form of autonomy in both the aesthetic and empirical domains. ${ }^{8}$ Let's distinguish between two forms of intellectual autonomy: direct autonomy and indirect autonomy. To have direct intellectual autonomy over a given judgment, we need to grasp all the reasons, evidence, and considerations which support the content of that judgment for ourselves. To have indirect intellectual autonomy over a judgment, we can acquire that judgment through testimony from a trusted source, provided that we grasp the reasons for our trust. Indirect autonomy is the weaker requirement: we need only understand our trust in the external sources of our judgments, rather than understanding the content of the judgments itself. ${ }^{9}$

In our life with the sciences, the best we can hope for is indirect autonomy over most of the domains on which we depend. Contemporary science is so vast that no individual can hope to possess direct intellectual autonomy over all the scientific judgments which they must use. As Elijah Millgram puts it, the character of modern epistemic life is dominated by

\footnotetext{
${ }^{8}$ I focus, in this paper, on explaining the asymmetry between the aesthetic and the empirical, leaving largely to the side the asymmetry between the aesthetic and the moral. This is because, while almost all agree about the direction of asymmetry in the aesthetic/empirical case, not all agree in the aesthetic/moral case. Elsewhere, I have suggested that our demand for autonomy is stronger in the aesthetic than the moral (Nguyen 2017). Others have suggested that our demand for autonomy is weaker in the aesthetic than the moral (Driver 2006), and others have suggested that they are precisely on a par (Howell 2014). I will make some tentative remarks on this topic at the end of this paper, but I will otherwise leave this topic for later discussion.

${ }^{9}$ This distinction drawn from my discussion of expertise and the fragmentation of intellectual autonomy (Nguyen 2018). The discussion of trust and intellectual autonomy is vast; for starting points, see (Hardwig 1985, 1991; Goldberg 2010)
} 
the hyperspecialization of expert domains. Non-scientists must trust the judgments of scientific experts without being able to understand those experts' reasons. And even among the specialists, each expert must depend on the judgments of other experts without being able to fully grasp the grounds for all those judgments for themselves. The doctor must trust the biologist, the chemist, and the engineers who made their instruments. Nobody can understand all the fields of science on their own; the best they can do is to manage their trust in others with some degree of autonomy (Millgram 2015; Nguyen 2018). We can now better articulate the key asymmetry: in empirical life we demand only indirect autonomy, but in aesthetic life we demand direct autonomy.

There are, then, two different possible specifications of the Autonomy Principle:

Direct Autonomy Principle: One ought to arrive at one's aesthetic judgments of an object through the application of one's own faculties and abilities, without the use of testimony. ${ }^{10}$

Indirect Autonomy Principle: One ought to arrive at one's aesthetic judgment of an object through the application of one's own faculties and abilities, including acquiring judgments about the objects through testimony, so long as the choice of testimonial sources arises through the application of one's own faculties and abilities.

\footnotetext{
${ }^{10}$ I take the Direct Autonomy Principle to be a stronger requirement than the requirement that is usually attributed to Kant. For example, Keren Gorodeisky suggests that Kant requires that an aesthetic judgment proceed from the judger's own pleasurable response, in addition to the judger's grasping of the merit of that response (Gorodeisky 2010). Notice that, in Kant's version, there is no requirement that the judger's pleasure or grasp proceed from their own self-directed inquiry; they could be led to it.
} 
My claim is that in aesthetic appreciation we demand the Direct Autonomy Principle. We do not make the analogous demand in empirical, scientific life; there, we only ask for the much weaker, indirect form of intellectual autonomy.

Why this difference? I will argue that it is because science and art appreciation have very different purposes. In art appreciation, we aim at making correct aesthetic judgments. But having correct judgments isn't the purpose of the practice. Our purpose is to engage in the activity of trying to make correct judgments. We shouldn't defer to aesthetic testimony because figuring it out for ourselves is the whole point. On the other hand, we demand indirect autonomy in empirical life because we significantly value getting things right, and that value often outweighs the values associated with doing things for ourselves.

The account also suggests a larger picture, which might help to illuminate the complex relationship between the Acquaintance Principle and the various forms of the Autonomy Principle. Let me briefly sketch that picture. Suppose, for the moment, that we accept the common view that the Acquaintance Principle captures a constitutive feature of aesthetic judgment. ${ }^{11}$ In that case, we could understand the two principles as arising from different considerations. The Acquaintance Principle concerns what it is to be an aesthetic judgment, while the Direct Autonomy Principle arises from our purpose in making aesthetic judgments. Let's call this the split-level view; it separates the norms involved into ones arising from the constitutive level of explanation and the value level. The split-level view would resolve the seeming competition between the Acquaintance Principle and the Direct Autonomy Principle. And it would explain why we think Audio Tour Brandon is missing some of the point of

11 This claim is widely, though not universally, accepted. Notice that, for those that reject the constitutive normativity of the Acquaintance Principle, all my claims concerning the Direct Autonomy Principle's relationship with value would still hold. 
aesthetic life, though we would allow that he was still engaged in aesthetic activity. He is not entirely outside the realm of the aesthetic as, say, would be somebody that invested in paintings for economic reasons, based on purchasing trends. He's in the right domain, but halfasleep at the wheel. The split-level view strikes me as quite plausible, but I will leave it aside for future exploration.

\section{What is the value in direct autonomy?}

Let's retreat to the more local claim, to which I will devote the rest of this paper. The Direct Autonomy Principle, I've proposed, can be explained by a particular story about the motivational structure of art appreciation: that the value of aesthetic appreciation lies in or arises from the processes of engagement involved in forming aesthetic judgments. 'Aesthetic engagement' here includes our higher-level cognition of aesthetic objects: searching for connections, rethinking interpretations, discovering affective resonances. It also includes lowlevel forms of engagement such as perceptual engagement: actively shifting one's attention from one perceptual detail to the next, and then assembling those details into a larger structure. And it includes the way these forms of engagement feed into one another, as my interpretation and affective responses influence where I direct my attention, and vice versa. Aesthetic engagement includes all the perceptual, cognitive, and affective processes we actively deploy on our way to generating an aesthetic judgment.

Here is my proposal: we perform the various aesthetic activities of perception and investigation for the sake of our involvement in the activity of seeking correct judgments, rather 
than for the sake of actually having made correct judgments. In other words, though the aesthetic activity of appreciation usually culminates in the issuance of aesthetic judgments, that activity is not made valuable by the issuance of those judgments or by their correctness. Rather, we aim at making correct judgments for the sake of engaging in the attempt to get them right. Let us call this the engagement account of aesthetic value. The engagement account states that the primary value of the activity of aesthetic appreciation comes from the process of generating judgments and not the end-product — the judgments themselves.

In some sense, the engagement account is quite intuitive. I listen to music for the sake of the listening itself, and not for the sake of having made correct judgment about the quality of the music. But this simple observation has many philosophical dividends. The account answers our question about the value of direct autonomy. The demand for direct autonomy is important because it encourages aesthetic engagement. Furthermore, the engagement account explains the asymmetry between aesthetic judgment and scientific judgment. The reason we defer to expert testimony in the sciences, but not in aesthetic appreciation, is that getting correct judgments is the primary source of value in the sciences. However, in the practice of aesthetic appreciation, getting correct judgments is less important than the processes we go through in forming those judgments for ourselves. ${ }^{12}$

\footnotetext{
${ }^{12}$ A complication: as Finnur Dellsén points out, we seem to require scientific experts to be directly autonomous when working within their own specialist domain, but we do not require such direct autonomy for their grasp of adjacent domains - even when they depend on and apply claims from those adjacent domains. The best explanation, argues Dellsén, is that science is guided by norms of long-term communal correctness, rather than norms of individual correctness. That is, if a scientist were interested in maximizing their own judgments' correctness, they should, in fact, always defer to the consensus view, even in their own terrain. However, it is crucial that we enforce norms of direct intellectual autonomy for experts in their own domain. These norms are vital for the long-term, collaborative pursuit of correctness. Outsiders need to use expert consensus as a guide, but the consensus of experts is only valuable if the experts have reasoned independently. The ideal arrangement for the long-term collaborative pursuit of correctness, then, is that we defer to others for facts outside of our own realm of expertise, but adopt norms of direct autonomy when inside our own realm of expertise (Dellsén 2018). The particular structure of the demand for autonomy that we find in science - direct autonomy for experts in their own domain, but indirect otherwise - is precisely what we
} 
What might the value be in directly autonomous aesthetic engagement? Let's step back a moment and consider our complicated relationship to aesthetic testimony and aesthetic judgment. Audio tours and other forms of critical guidance can play a crucial role in a healthy, well-balanced aesthetic life. There are many felicitous uses of aesthetic testimony and many contexts where we happily relax our demand for aesthetic autonomy. The problem for Brandon is not in his use of the audio tour, but in his disinclination to move past it. Much, then, seems to depend on how exactly the aesthetic appreciator uses aesthetic testimony. Is their use open-ended or closed-ended? Some ways of using aesthetic testimony seem to quickly terminate one's aesthetic engagement. For example, when two friends are involved in an aesthetic dispute, it seems wrong to simply turn to some expert to settle the matter. Suppose we were to disagree about the aesthetic value of Satoshi Kon's psychedelic anime Paprika, and I tried to settle it once and for all by consulting the review aggregation site Rotten Tomatoes and pointing out that $83 \%$ of critics had rendered a positive judgment. The way I'm using aesthetic testimony here skims off a supposedly authoritative overall evaluation of the film, while leaving me out of touch with the particular reasons for that evaluation. This relationship to testimony cuts me off from the specific attention-guiding features of critical discussion. It terminates my engagement with the aesthetic details..$^{13}$ If, on the other hand, I reacted to our dispute by reading essays from sensitive film critics, re-watching the movie while attending to the features those critics pointed out, and then used what I learned in further engagements with film, then my use of testimony seems unproblematic. That is an engagement-encouraging use of aesthetic testimony. A problem with Audio Tour Brandon is

should expect for a social practice oriented towards producing long-term, collective correctness. But notice that with aesthetic appreciation, we demand something very different: direct autonomy for all.

13 This comment is indebted to an analysis of Matt Strohl's (Strohl 2017). 
not simply that he lets his attention be directed by an authoritative source. Rather, it is that he terminates his engagement there, rather than using those authoritative directions as springboards to further engagement. ${ }^{14}$

But problem here isn't simply about how deference can limit the quantity of engagement available to the guided appreciator. Fully autonomous engagement seems qualitatively better. A crucial part of the activity of aesthetic appreciation lies not only in the content and order of attention, but in the fact that the appreciator actively chooses where to direct their own attention. An autonomous appreciator is an agent with respect to their own attention. And that agency helps to cultivate a different kind of attention and a different mental relationship with the object of their attention. This is, in a very intuitive sense, what it means to be truly engaged. One analyzes the input and decides which features to attend to next, which possibilities to explore. One inhabits one's investigations more fully when one has to guide them from moment to moment.

There is a useful parallel in Mill's discussion of the value of free speech. Mill thought that one needed to constantly defend one's beliefs in order to keep them alive. Without the pressure to actively rethink, reconsider, and reformulate, one's beliefs would fall into habit and routine; they would transition from live beliefs into mere words — 'the shell and husk only'. Beliefs need to be constantly defended through a process of analysis and inquiry to maintain 'a livelier feeling of the meaning of their creed'. ${ }^{15}$ Aesthetic engagement strikes me as playing a similar role. Active engagement keeps one's aesthetic judgments alive in one's mind. ${ }^{16}$

\footnotetext{
${ }^{14}$ This distinction loosely modeled on some suggestions from Philip Nickel on the nature of moral testimony (Nickel 2001). I have offered some discussion of Nickel's account (Nguyen 2010).

15 From On Liberty (Mill 1967, p. 247-9). My understanding of these passages follows from (Millgram 2004, p. 172-3).

${ }^{16}$ Alex King offers a similar account of active aesthetic engagement in her discussion of the virtues of aes-
} 
Notice that valuable engagement can arise in the process of rendering either a positive or negative judgment. It can be a valuable form of engagement to critically analyze a movie and come, after significant consideration, to realize that it is hollow and manipulative. The engagement account, then, is quite distinct from those views in which the value of aesthetic appreciation is to be found exclusively in positive aesthetic judgments, or the experience of valuable aesthetic properties. ${ }^{17}$ Such accounts restrict the value of aesthetic appreciation to making correct judgments of aesthetically good objects. The engagement account, I think, better captures the varied paths to aesthetic value. For example, I used to have a very uncritical relationship with food. I ate TV dinners and fast food. I liked food that was crunchy and salty, and that was the end of the matter. Then, I took a trip with a more culinarily cosmopolitan friend and become exposed to more subtle, complex, and interesting food. My sensibilities developed, my tastes transformed. When I returned to my small town, with its limited repertoire of fast food joints and frozen food, those same-samey burgers and fish sticks had lost their appeal. After that, I had to travel a long way to find any culinary satisfaction. As a result of my culinary awakening, I found myself making far fewer positive aesthetic judgments. If the quality of my aesthetic life was dependent simply on the number of positive aesthetics judgments I made, then my aesthetic life would have simply gotten worse. But this seems like the wrong way to think about this story. I'd learned something, and my aesthetic

thetic subtlety. We seem to value subtlety in art. The central feature of aesthetic subtlety is that it is epistemically demanding. Why do we value subtlety? The answer, she suggests, is that subtlety makes the appreciator work for it. Subtlety promotes active engagement in the appreciator, where heavy-handedness discourages agency in the appreciator (King 2017). King's discussion here dovetails nicely with my own. If aesthetic engagement is the source of value, then heavy-handedness is the failure of the artwork to promote engagement, while deference is the failure of the appreciator to pursue valuable engagement when it's available.

17 One such view can be found in Kendall Walton's claim that the aesthetic value of an object lies in its capacity to appropriately produce aesthetic pleasure. Aesthetic pleasure, on his account, is quite specific: it is the pleasure one takes in one's admiration or positive evaluation of something, when one recognizes that the object earned that pleasure (Walton 1993, p. 504-9). 
life had gotten better in some important ways, even if that didn't have a clear cash value in terms of an increased quantity of positive aesthetic judgments.

A proponent of such an account of value could try to respond by saying that the value of greater understanding lay in my clearing the ground of the crud and making room for better pleasures. But notice that I only get that pay-off if I have adequate access to better quality aesthetic objects - which isn't the case in my food story. Consider, instead, what the engagement account has to say about this sort of life arc. The engagement account is free to distribute the value through all sorts of activities involved with generating judgments. Rendering a negative judgment of an object through sensitive engagement with its particularities can, in and of itself, be a valuable activity. Of course, a life full of only negative judgment of boring objects would be lacking many distinctive kinds of aesthetic value; it would lack, for example, the values associated with having deep and lasting engagements with a complex, subtle works. But coming to have negative judgments through an engaged process is certainly part of the value story.

This line of thinking`opens the door to all sorts of other possibilities. For example: we might have thought that we had long conversations about art in order to get the right judgments. The engagement account suggests, instead, that we might be pursuing correct judgments so that we can have all these lovely, careful conversations.

\section{Correctness and engagement}

How, then, are we to square an engagement-centric picture of value with the apparent 
drive for aesthetic correctness? I mean correctness here in several senses. We want to attribute the right aesthetic properties to the work. We want to have the correct overall judgments of the aesthetic quality and worth of a work. And we want those judgments and attributions to be responsive to genuine details in the work. And, as Fabian Dorsch points out, we expect our aesthetic interlocutors to be able to provide reasons for their aesthetic judgments, to defend their claims and point out supporting details - or we lose respect for them (Dorsch 2013). ${ }^{18}$ What's more, we don't simply stop when we have a pleasing response or interpretation of a work; we push on to make sure that our response is sensitive to the complex actuality of the work. Without that drive to correctness, we would be tempted to stop thinking about the work as soon as were pleased by it. We would not have any reason to push on, since we might end up discovering some subtle flaw that shattered our enjoyment.

One might be then tempted to reason in the following way: since my actions are oriented towards the goal of correctness, then the purpose of the practice of aesthetic judgment must itself be correctness. But I do not think that this is right. The goal at which we aim during an activity is not necessarily the same as our purpose for taking up the activity, nor is achieving that local goal the only possible source of value for an activity. Some people try to catch fish to achieve a certain meditative state of mind and some people try to climb mountains for the sake of their health. I myself relax after a hard day of philosophy by doing some rock climbing. Notice that I pursue my larger purpose - relaxation - by focusing on a local goal - getting to the top of the rock. But it doesn't actually matter for my purposes if I really do get to the top; it only matters that, in trying to get to the top, I managed to clear my head. ${ }^{19}$

\footnotetext{
18 See also (Cavedon-Taylor 2017) for a useful further discussion.

${ }^{19}$ Discussions of such structures have sometimes come up under discussions of self-effacing ends - that
} 
This complex relationship between goals and purposes is, I think, easiest to see when they are formalized in games. In every game, there is a goal. For simplicity's sake, let's say that the goal of a game is winning. There are two kinds of motivational states one might take towards game-play. First, one might play the game for the sake of the value of winning or what follows from winning. Call this achievement play. Second, one might take on the goal of winning for the sake of the activity of trying to win. Call this striving play. We can find evidence of striving play in many of our game-playing practices. First, consider our long-term manipulations of our capacity to win a game. When I play board games with my spouse, we both try our best to win. But, so long as our matches are close and exciting, we will avoid, say, reading strategy guides on our own. We are trying not to outpace each other. If one of us become too much more skillful than the other, then the contest would lose its savor. This reveals that we are striving players and not achievement players. Winning is not the point for us. We each pursue winning locally, during the game itself, but in the long term, we manipulate our abilities, not for the sake of maximizing our wins, but for the sake of the quality of the struggle. ${ }^{20}$

Next, consider what we might call stupid games. A stupid game is one where the best part of the game is losing, but failure is only fun if you were actively pursuing the win. Examples of stupid games include Twister, the children's game of Telephone, and many drinking games.

is, ends that cannot be achieved through direct pursuit (Parfit 1984, p. 23-4; Keller 2007; Annas 2008; Pettigrove 2011, p. 192-3).

20 The discussion of striving play in this section is a condensed version of my account of the motivational structure of game-play, developed at length elsewhere (Nguyen 2019; 2020). The present paper has its origins in some invaluable comments by Servaas van der Berg, who suggested that my discussion of games and striving could fruitfully be brought to bear on some key questions of aesthetics. Van der Berg has since applied my account of striving play to offer his own account of the distinctiveness of appreciative perception. Appreciation, he argues, involves the special inverted motivational state, which explains its distinctive mode of attentional guidance (Van der Berg 2019). I take our discussions to be compatible and complementary, though they are argumentatively independent. 
With stupid games, we must aim at success, but what we actually want to do is to fail in the attempt. In stupid games, our goal and purpose clearly come apart. If we can play stupid games, then striving play must be possible.

Striving play involves a motivational inversion. In normal practical life, one takes the means for the sake of the ends. In striving play, one selects the ends for the sake of the means it puts one through. It is simple, then, to square the engagement account with the apparent goal of correctness. We need only allow that aesthetic appreciation is a striving activity. In aesthetic appreciation, we aim at correctness, but correctness is not the purpose. It is only to right goal to adopt in order to become engaged in a desirable form of activity.

I am not here claiming that the practice of aesthetic appreciation is a game, but I am claiming that it has a similarly inverted motivational structure. Importantly, this does not commit us to the view that aesthetic engagement is intrinsically valuable. Let's return to games for the moment. The distinction between striving play and achievement play is not the same as the distinction between intrinsic and extrinsic value. The intrinsic/extrinsic value distinction concerns whether something is valuable in itself or whether it is valuable as a means to an end. The striving/achievement play distinction, on the other hand, concerns where that value adheres. It is possible to be an intrinsic achievement player and play for the value of the win itself, or to be an extrinsic achievement player and play for the value of what follows from the win, like money or honor. Similarly, it is possible to be an intrinsic striving player and play for the intrinsic value of the striving itself, or an extrinsic striving player and play for the value of what follows from striving - as I might if, say, I ran marathons for my health.

Thus, in claiming that aesthetic appreciation is a striving activity, I am only claiming that 
the value adheres to the activity of appreciation, rather than to the ends of that activity. I leave open the question of whether that activity is intrinsically or extrinsically valuable. Certainly, one could think that the activity was valuable in itself. However, the engagement account is also compatible with views that attribute extrinsic value to aesthetic engagement. Consider, for example, the lingering effect of aesthetic experiences - for example, the fact that, after a day of looking at paintings in museums, one's experiences of the rest of the world will be enhanced (Nanay 2016, p. 16-17). The pursuit of that positive aftereffect still counts as a striving activity, so long as it is the process of engagement that creates the lingering aftereffect. I have reason to judge for myself, rather than deferring to another, since it is the act of judging for myself which leads to the extrinsically valuable consequence..$^{21}$

Of course, this invites a further question: why is the pursuit of aesthetic correctness a valuable activity? One might think that aesthetic engagement would be improved if it were freed from the burden of correctness. Why not just let our imagination run free and ascribe to the world whatever aesthetic properties and make whatever aesthetic judgments we wished?

The analogy with games is particularly useful here. In Bernard Suits's account of games, to play a game is to take on the pursuit of some goal, along with some unnecessary restrictions and obstacles on achieving that goal, for the sake of the activity they make possible (Suits 2014). The goals of games aren't usually valuable in themselves. The nature of a gamegoal can usually be best explained in terms of the nature of the activity it inspires. In basketball, there's no special value in getting this ball through that hoop in and of itself. We want to

21 This is why I do use the language of 'striving' rather than that of 'autotelicity'. The latter term refers specifically to intrinsically valuable striving activities. 
get the ball through the hoop while facing opponents and obeying the dribbling constraint because we want to engage in the activity of dodging, jumping, and shooting. We want to get to the top of this cliff by going the hard way - up the steep face, using only our hands and feet - because we want to engage in the particular activity of rock climbing. We want to be forced to coordinate delicate balance and powerful, graceful, precise movement in a unified effort to surmount the challenges of the rock. ${ }^{22}$ Notice the relationship here between the activity, the goal, and the rules. In free climbing, the climber must ascend only by using their hands and feet, applied only to the rock itself. ${ }^{23}$ They are not allowed to pull on the rope or the various pieces of gear attached to the rock; the rope is only there as a safety measure. Some novice climbers complain about these strange restrictions. The requirement to ascend by using only the rock strikes them as annoyingly arbitrary. Why submit to these restrictions, when one could just swing around on the rope as one pleases? Experienced climbers, however, understand the purpose of these restrictions. When you are allowed to ascend by pulling on the rope and the gear, then you end up repeating the same sorts of movements on any sort of rock. The requirement to ascend using only features of the rock itself forces the climber to attend to the distinctive details of each different rock face. It forces the climber to invent new and creative solutions in response to the widely varying details of the rock.

We can offer a similar explanation for our practice of aesthetic appreciation. As with rock climbing, aesthetic appreciation is a practice which involves pursuing a goal inside certain

\footnotetext{
22 One might wish to say here that the game goal must be combined with the constraints to produce the activity. Importantly, Suits's account of a game goal folds in the notion of a constraint. A lusory goal, in Suits's account, is some desirable state of affairs which may only be reached while obeying certain constraints. 'Making a basket', in basketball, only occurs when one is following the rules (36-43).

${ }^{23}$ Many non-climbers confuse 'free climbing,' which is climbing with the hands and feet only, while using a safety rope,' with 'free soloing,' which is climbing with no safety rope at all. There is a form of climbing in which one was allowed to pull on the gear - 'aid climbing'. That style was common in the early days of climbing but has now been largely abandoned in favor of free climbing.
} 
restrictions. We are to try to arrive at correct aesthetic judgments through the use of our own faculties, without deferring to others. As with climbing, the goal and the restrictions can be explained in terms of the form of activity they inspire. The aim of getting correct aesthetic judgments via our own faculties and abilities drives us towards a very particular sort of activity: one that is oriented around sensitivity, refinement, care, and responsiveness to detail. If my aesthetic activities weren't oriented towards getting it right, I would be free to imagine and impose as I please. I would have no motivation to stick to the details of the object and thus no reason to study that object with care. Such free-form activity is likely to satisfy one set of interests - say, in having imaginative freedom, unfettered creativity, and the like. But we bring to bear an entirely different set of capacities when we aim at correct aesthetic judgment. In aesthetic appreciation, we engage in perception and cognition under the requirement of loyalty to the details of external objects in all their peculiar differentness. The best explanation of our demand for direct autonomy in aesthetic appreciation, then, is that we value the specific form of activity involved in pursuing correct aesthetic judgment. We value the process of hunting for subtle details that we missed the first time around, of struggling to create interpretations that fit with the rich actuality of the world.

The parallel with games is, I think, particularly useful in thinking about why we avoid deferring to aesthetic testimony and aesthetic experts. As Suits points out, game-play is, by its very nature, essentially inefficient with respect to its in-game goals (35-36). We aim at the end of crossing the finish line of the marathon, with the restrictions of not taking a taxi or riding a bicycle, in order to engage in the activity of running. Aesthetic appreciation is, in a similar way, inefficient in its pursuit of correctness. If we thought the goal of aesthetic appreciation was correctness, then we would be interested in maximally efficient pathways to 
that goal, such as being guided by experts or acquiring beliefs through testimony. We refuse to defer precisely because that restriction drives us towards a particular form of valuable activity. The aesthetic appreciator who defers to testimony, then, is making the same mistake as the marathon runner who takes a taxi to the finish line. They mistakenly take the local goal for the purpose of the activity and thereby miss out on the real value. Their shortcut defeats the whole point.

The parallel structure will be even clearer if we consider more overtly intellectual games. When I am reading a certain sort of traditional mystery novel, I am trying to figure out who the culprit is ahead of the big reveal. Notice a few things about the activity of puzzling through a mystery novel. First, there is a correct answer to my questions. Second, I don't value knowing those answers simply for the sake of the knowledge itself - otherwise I would turn to the last page or read the spoilers on Wikipedia, thus saving myself the time and effort of actually reading the book. Third, the inverted motivational structure of striving explains why I don't simply look up the answer online. ${ }^{24}$ Puzzling through a mystery novel is a striving activity. We chase the right answer by inefficient means for the sake of the struggle. The practice of aesthetic appreciation involves a similar inverted value structure. We make our judgments autonomously because deference to another would be like flipping to the end of the book.

We now have an explanation for the so-called pessimistic intuitions about aesthetic testimony. Why does it seem so wrong to us to acquire aesthetic judgments through testimony? It isn't because we cannot transmit aesthetic knowledge through testimony. Rather,

\footnotetext{
24 Some people dislike the mystery, and only want the story, and so do flip to the end. In this case, I suggest, they are engaged with a mystery novel as a work of fiction, and not with its game aspect.
} 
it is because getting that knowledge through testimony would defeat the whole point of the exercise.

Notice, too, that the engagement account has the resources to explain the complexities of our variable willingness to use testimony from aesthetic experts. For example: we seem willing to use expert testimony to give us recommendations about what movies to watch and which restaurants to try, but we seem unwilling to defer to their expertise in forming our own judgments. ${ }^{25}$ This is nicely explained by the engagement account. Experts are good guides to the sorts of objects that can sustain a long, involved and satisfying engagement. So when we trust their recommendations and pay attention to what they recommend, we are more likely to have such engagements. But if we defer to their judgments rather than coming up with our own, then we will skip over the very process of engagement which we value. The best way to use testimony to foster quality engagement, then, is to use testimony as a guide for where to spend our attention, but not as a substitute for the ensuing process of judgment.

The engagement account can also explain another asymmetry, which has been called Kant's problem of aesthetic testimony. Suppose I have listened to Migos's Atlanta trap classic Culture a handful of times and found it repetitive and dull. Then, my musically sensitive friend and trusted confidante tells me that it is, in fact, a revolution in rap because of how it deploys its rhythmic patterns to create new kinds of musical space, and that I've missed its subtle, but profound, groove. This gives me a reason to listen again and reconsider my judgment. As Hopkins puts it, we take contrary aesthetic testimony to be capable of inspiring doubt - to give us reason to reconsider something. But I will not, of course, simply adopt my

25 See the discussion of recommendations and autonomy in (Hopkins 2011, p. 154-5; Nguyen 2017) and the distinction between aesthetic judgment and aesthetic belief in (Gorodeisky and Marcus 2018, p. 135-7). 
musically sensitive friend's judgment outright. Here is the problem: what force could aesthetic testimony have, that it could provide negative weight for inspiring doubt but, at the same time, fail to provide a positive basis for deference (Hopkins 2001)? ${ }^{26}$ As Keren Gorodeisky and Eric Marcus put it, Kant's Problem is how we thread the needle between doubt and deference. It looks like any explanation which can group the doubt from testimony will also force us to defer to contrary judgments, when the source is sufficiently expert. Gorodeisky and Marcus offer a complex Kantian solution for threading that needle (Gorodeisky and Marcus 2018, 122-137). But the engagement account offers us a different, and considerably simpler, solution. We have sculpted a practice of aesthetic appreciation with norms set to drive us towards greater engagement. We permit testimony to raise doubt because adopting that norm will drive us toward greater engagement. That norm will generate reasons to look again and increase the likelihood of paying attention to works that can sustain deeper engagement. But we don't permit deference to testimony in forming our judgment because that would cut off any deeper engagement. The norm that permits doubt from testimony is engagement-enhancing, but the norm that permits deference from testimony is engagementterminating. The permission to doubt from testimony, but the prohibition on deference to testimony, are good norms to have because, together, they sculpt the practice of aesthetic appreciation in a way that supports greater engagement.

Importantly, the engagement account is intended only as an analysis of the practice of aesthetic appreciation. There are other practices in the aesthetic domain with other purposes, to which the engagement account does not apply. Consider, for example, the practice of art history. Art history is oriented towards the generation of correct historical facts; it is,

${ }^{26}$ For related discussions, see (McGonigal 2006; Robson 2015). 
therefore, not a striving activity. Thus, the account l've offered can explain the practice-dependent variability of our demand for strong autonomy. When my friends and I are in a museum, talking about the absence of presence of gracefulness in a particular painting, we ought not to defer to the judgments of others. On the other hand, if I am an art historian and I am trying to track the movement of a particular style through various places, I sometimes ought to defer. ${ }^{27}$ The reason we hold fast to the Direct Autonomy Principle in the appreciation case, but not in the art history case, is that we are invoking different practices with different purposes. The value in art appreciation lies more in the process of judgment than in having correct judgments. Art historians, on the other, are more interested in the correct judgments themselves. These different purposes indicate different norms for autonomy.

\section{Conclusions}

One might then ask why we are expending all this striving effort here, on such an odd pursuit? Why spend all this energy cognitively struggling over paintings, and not over, say, solving world poverty? If we don't care about the correctness of aesthetic judgments, ought we not get our cognitive kicks where it might be of some use to the world? Consider a parallel worry concerning games. Thomas Hurka argues that the value of playing games comes from their difficulty. Thus, so long as we're not in utopia, it will be better to do things that are both difficult and instrumentally good. For example, if playing chess and working to cure cancer are both equally difficult, then the latter is to be preferred, for it is both difficult and useful (Hurka 2006).

${ }^{27}$ Case adapted from (Nguyen 2017, p. 25-26). 
Hurka's conclusion, I think, misses much about the special value of games. The right response to Hurka is that the value of games lies not only in their difficulty, but in the experiential quality of that difficulty — in whether the struggle is interesting, dull, or fascinating. ${ }^{28}$ Games are special because, in games, we are significantly freer to shape the nature and demands of the task to suit us. In ordinary practical life, our instrumental engagement is significantly constrained by the goal and the inflexibility of the world. The world can render our pursuits exhausting, dull, and full of miserable grinds. The search for scientific truth, for example, might involve some incredibly satisfying intellectual epiphanies, but the nature of the world means that it will also involve a lot of mucking about with spreadsheets, fixing instruments, and digging through hard soil under the brutal summer sun. Chess, on the other hand, is a practical activity optimized for the pleasures and satisfactions of cognition. The nature of its goal and the logic of its mechanics shape a very particular practical environment - one that has been made specifically for our cognitive delight. In ordinary practical life, we must bend ourselves and desperately try to fit our abilities to the practical demands of the world. In games, we can design a practical world to fit our abilities and our inclinations. ${ }^{29}$

Something similar is true, I suggest, with the arts. The activities and states involved in rendering aesthetic judgments - investigation, sensitivity to perceptual and cognitive details, interpretation, empathy - are also instrumental resources. ${ }^{30}$ In ordinary practical life, our use of these resources is beholden to the instrumental demands of the world. The arts, on the other hand, are precisely where we can mold the objects of judgment - and also pick

\footnotetext{
${ }^{28}$ For a discussion of this point, see (Tasioulas 2006).

${ }^{29}$ For an extended discussion of this point, see (Nguyen 2019, p. 429-38; 2020).

30 Tantalizingly, Suits's definition of play is: ' $\mathrm{x}$ is playing if and only if $\mathrm{x}$ has made a temporary reallocation to autotelic activities of resources primarily committed to instrumental purposes' (Suits 1977, p. 123-4).
} 
the constraints on how we are to judge those objects - in order to shape the activity of deploying these instrumental resources to our own satisfaction.

I hope it is clear by now that the demand for direct autonomy isn't unique to aesthetic appreciation. We should expect demands for indirect autonomy to dominate in practices oriented towards the value of correctness itself - the empirical sciences, history, and the judicial system. We should expect demands for direct autonomy to dominate in those practices oriented towards the value of engagement in a process - aesthetic appreciation, but also games, exercise, education, and more. We should expect to find a demand for direct autonomy for any activity with the motivational structure of striving, rather than of achievement.

Much of the discussion of the asymmetry between empirical judgment and aesthetic judgment has presumed that our peculiar attitude towards aesthetic testimony arises from features unique to the aesthetic domain. Instead, my account suggests that it is a general feature of striving activities. Aesthetic appreciation is one type of striving activity; but there are others. And there are non-striving approaches to the aesthetic, as well. This helps explains another asymmetry: why we are more willing to use aesthetic testimony in art-historical contexts, but less willing to in art-appreciative contexts. An account that made autonomy a necessary part of any aesthetic judgment would not be able to explain that secondary asymmetry. The engagement account, however, has a tidy explanation: art appreciation is a striving activity, but art history is not.

The engagement account might also explain a crucial and under-explored aspect of our relationship with art and the aesthetic. We seek to understand works, but we are disappointed when we reach that understanding too quickly. We wish to understand artworks, but when the artworks are too easily understood, we judge them poorly — we call them 
'shallow' or 'thin'. By many accounts, the greatest works are the ones that are the most endlessly accommodating of interpretation and inquiry. I love the poet Tu Fu precisely because I try to understand him and I never get to the end; every time I re-read a verse, I find some new subtlety or connection. The engagement account explains this: correct aesthetic judgment is the goal, but not the purpose. Thus, we are disappointed when our fascinating journey is cut off by our too-quick arrival at the apparent destination. At the same time, we cannot undermine the sincerity of our attempts at correctness to forestall such a finish, for that would undermine our absorption in the investigative attempt. ${ }^{31}$ We want objects which we can sincerely try to understand thoroughly, but which endlessly defy a complete understanding. We want subtlety, depth, and mystery. But the engagement account also helps to explain why most beloved artworks are, typically, not purely ambiguous. For a blank or impossibly cryptic work, the process of trying to understand cannot even get off the ground. What we seem to desire is something balanced on the razor's edge between incomprehensible and shallow - something which presents the possibility of understanding as an apparent, but ever-elusive target. If we simply valued having correct judgments, we should seek easy-tounderstand works. If we valued having correct but difficult judgments, we should seek works that were difficult to understand, but which came with assurances that the task of comprehension would eventually terminate. Instead, we seem have the greatest esteem for those works that never admit of a completed and finalized set of judgments. We cherish a sort of aesthetic bottomlessness. Our love of this tempting, but ever-retreating target, is best explained by attributing to us a value for the pursuit, and not the having, of correct aesthetic

\footnotetext{
${ }^{31}$ For a further discussion of this point in the context of game-play, see (Nguyen 2019, p. 440-6).
} 
judgments. $^{32}$

And here, I think, we can find a hint about the difference between moral autonomy and aesthetic autonomy. The demands of moral autonomy may forbid us from simply deferring outright. But moral autonomy is usually taken to be compatible a relatively high degree of guidance, especially for the sake of correctness. ${ }^{33}$ In the practice of aesthetic appreciation, on the other hand, we are more suspicious of thoroughgoing guidance and place a relatively higher importance on self-direction over correctness. Imagine how we would feel if the field of philosophical ethics, after millennia of work, finally came to an agreement about the right ethical theory, and produced a text with careful and convincing arguments that cleared up the major moral dilemmas and settled the major questions. I think we might feel rather relieved; we might even feel that philosophy had partially redeemed itself. I would certainly wish to read it to judge its arguments for myself, and I would be happy if I were to be convinced and all my moral worries settled once and for all. And I would wish to teach this book to my undergraduates. I would certainly want them to read the arguments and consider them for their own, to be convinced through their own process of reasoning — but the availability of convincing, conclusive arguments here would be a good thing. How we would feel, on the other hand, if the world of literary scholarship came out with a conclusive analysis of Joyce's Ulysses, which settled every debate, answered every question, and disambiguated every term, in convincing and comprehensible arguments? I think I would feel rather sad — that the world of the arts had been substantially diminished. And I, for one, would not wish to

\footnotetext{
32 For some suggestive resonances to this point, see (Nehamas 2010).

33 The terrain here is vast. Some key accounts include (Jones 1999; McGrath 2011; Nickel 2001; Zagzebski 2012). For my own take on moral autonomy and testimony please see (Nguyen 2010). Finally, note that (Driver 2006) has considered the asymmetry between aesthetic and moral testimony, but runs it in the opposite direction - she thinks we care less about autonomy in aesthetic judgment, because we are willing to act on recommendations. Hopefully this paper shows that the issue is more complicated than that.
} 
read it. ${ }^{34}$ We pursue moral judgments with the hopes of getting it right, but we pursue aesthetic judgments for the sake of the activity of engagement. ${ }^{35}$

\section{Bibliography}

Annas, Julia 2008, 'Virtue ethics and the charge of egoism', in P. Bloomfield (ed.), Morality and Self-interest (Oxford: Oxford University Press)

Budd, Malcolm 2003, 'The acquaintance principle', in The British Journal of Aesthetics 43 (4): 386-392

Cavedon-Taylor, Dan 2017, 'Reasoned and unreasoned judgment: On inference, acquaintance and aesthetic normativity', in British Journal of Aesthetics 57 (1): 1-17

Dellsén, Finnur 2018, 'The Epistemic Value of Expert Autonomy', in Philosophy and Phenomenological Research <https://doi.org/10.1111/phpr.12550>

Dorsch, Fabian 2013, 'Non-inferentialism about justification - the case of aesthetic judgments', in Philosophical Quarterly 63 (253): 660-682

Driver, Julia 2006, 'Autonomy and the asymmetry problem for moral expertise', in Philosophical Studies: An International Journal for Philosophy in the Analytic Tradition 128 (3): 619-644.

Ginsborg, Hannah 2015, The Normativity of Nature: Essays on Kant's Critique of Judgment (Oxford: Oxford University Press)

Goldberg, Sanford 2010, Relying on Others: An Essay in Epistemology (Oxford: Oxford University Press)

Gorodeisky, Keren 2010, 'A new look at kant's view of aesthetic testimony', in British Journal of Aesthetics 50 (1): 53-70

Gorodeisky, Keren and Eric Marcus 2018, 'Aesthetic rationality', in The Journal of Philosophy 115 (3): 113-140

Hardwig, John 1985, 'Epistemic Dependence', in Journal of Philosophy 82 (7): 335-349

__— 1991, 'The Role of Trust in Knowledge', in Journal of Philosophy 88 (12): 693-708

34 This discussion is the beginnings of a response to Hopkins's discussion of the autonomy requirement. Hopkins suggests that one way to ground aesthetic pessimism is to hold that aesthetic judgments, like moral judgments, are subject to requirement to grasp the relevant grounds for oneself. Note that in Hopkins's account, the aesthetic requirement and the moral requirement have a similar degree of restrictiveness. What I've just said here weighs against that parallel. Thinking about the self-directedness of autonomy reveals that our requirement for aesthetic autonomy is, in fact, stronger than our requirement for moral autonomy. The engagement account offers us a way to say why. Engagement is the primary source of value in aesthetic life, in a way that it is not in moral life.

35 I'd like to thank, for their invaluable contributions: Dan Cavedon-Taylor, Julianne Chung, Anthony Cross, Adrian Currie, Finnur Dellsen, John Dyck, David Friedell, Kristina Gerhman, Keren Gorodeisky, Sarah Hegenbart, Alex King, Robbie Kubala, Kevin Lande, Samantha Matherne, Erich Matthes, Aaron Meskin, Shannon Mussett, Dominic McIver Lopes, Nick Riggle, Guy Rorbaugh, Elizabeth Scarborough, James Shelley, Brian Soucek, Eric Stencil, and Matt Strohl. I'd especially like to thank Servaas van der Berg, whose insights planted the crucial seed for this paper. 
Hopkins, Robert 2001, 'Kant, quasi-realism, and the autonomy of aesthetic judgment', in European Journal of Philosophy 9 (2): 166-189

- - 2011, 'How to be a pessimist about aesthetic testimony', in Journal of Philosophy 108 (3): 138-157

Howell, Robert 2014, 'Google Morals, Virtue, and the Asymmetry of Deference,' Noûs 48 (3): 389-415

Hurka, Thomas 2006, 'Games and the good,' in Proceedings of the Aristotelian Society, Supplementary Volumes 40 (1): 217-264 78

Jones, Karen 1999, 'Second-Hand moral knowledge', in Journal of Philosophy 96 (2): 55-

Keller, Simon 2007, 'Virtue ethics is self-effacing', in Australasian Journal of Philosophy 85 (2): 221-231

King, Alex 2017, 'The virtue of subtlety and the vice of the heavy hand', in British Journal of Aesthetics 57 (2):119-137

Konigsberg, Amir 2012, 'The acquaintance principle, aesthetic autonomy, and aesthetic appreciation', in The British Journal of Aesthetics 52 (2): 152-168

Laetz, Brian 2008, 'A modest defense of aesthetic testimony', in The Journal of Aesthetics and Art Criticism 66 (4): 355-363

Livingston, Paisley 2003, 'On an apparent truism in aesthetics', in British Journal of Aesthetics 43 (3): 260-278

Lopes, Dominic 2005, Sight and Sensibility: Evaluating Pictures (New York: Oxford University Press) Press)

2018, Being for Beauty: Aesthetic Agency and Value. (Oxford: Oxford University

Lord, Errol 2016, 'On the rational power of aesthetic testimony', in British Journal of Aesthetics 56 (1): 1-13

McGonigal, Andrew 2006, 'The autonomy of aesthetic judgment', in British Journal of Aesthetics 46 (4): 331-348

McGrath, Sarah 2011, 'Skepticism about moral expertise as a puzzle for moral realism', in Journal of Philosophy 108 (3): 111-137

McKinnon, Rachel 2017, 'How to be an optimist about aesthetic testimony', in Episteme. 14 (2): $177-196$

Meskin, Aaron 2004, 'Aesthetic testimony: What can we learn from others about beauty and art?', in Philosophy and Phenomenological Research 69 (1): 65-91

- - 2007, 'Solving the puzzle of aesthetic testimony', in M. Kieran and D. M. Lopes (eds.) Knowing Art (Dordrecht: Springer)

Mill, John Stuart 1967-1989, The Collected Works of John Stuart Mill. (Toronto/London: University of Toronto Press/Routledge and Kegan Paul)

Millgram, Elijah 2004, 'On being bored out of your mind', in Proceedings of the Aristotelian Society 104:165-186

- - 2015, The Great Endarkenment: Philosophy for an Age of Hyperspecialization (New York: Oxford University Press)

Nanay, Bence 2016, Aesthetics as Philosophy of Perception (Oxford: Oxford University Press)

Nehamas, Alexander 2010, Only a Promise of Happiness: The Place of Beauty in a World of Art (Princeton: Princeton University Press) 
Nguyen, C. Thi 2010, 'Autonomy, understanding, and moral disagreement', in Philosophical Topics 38 (2): 111-129.

$19-36$

- - - 2017, 'The uses of aesthetic testimony,' in The British Journal of Aesthetics 57 (1):

- - - 2018, 'Expertise and the fragmentation of intellectual autonomy', in Philosophical Inquiries 6 (2): 107-124

- - - 2019, 'Games and the art of agency', in Philosophical Review 128 (4): 423-462

- - - 2020, Games: Agency as Art (New York: Oxford University Press)

Nickel, Philip 2001, 'Moral testimony and its authority', in Ethical Theory and Moral Practice 4 (3): 253-266

Parfit, Derek 1984, Reasons and Persons (Oxford: Oxford University Press)

Pettigrove, Glen 2011, 'Is virtue ethics self-effacing?', in The Journal of Ethics 15 (3): 191207

Ransom, Madeleine 2019, 'Frauds, posers, and sheep: A virtue theoretic solution to the acquaintance debate', in Philosophy and Phenomenological Research 98 (2): 417-434

Robson, Jon 2015, 'Norms of belief and norms of assertion in aesthetics', in Philosopher's Imprint 15 (6): 1-19

Strohl, Matt 2017, 'Against Rotten Tomatoes', in Aesthetics for Bird <https://aestheticsforbirds.com/2017/09/21/against-rotten-tomatoes/>

Suits, Bernard 1977, 'Words on play', in Journal of the Philosophy of Sport 4 (1): 117-131

- - 2014, The Grasshopper: Games, Life and Utopia, $3^{\text {rd }}$ ed. (Peterborough: Broadview)

Tasioulas, John 2006, 'Games and the good II', in Proceedings of the Aristotelian Society 80: $237-264$

Todd, Cain 2004, 'Quasi-realism, acquaintance, and the normative claims of the aesthetic', in British Journal of Aesthetics 44 (3):277-296.

Van der Berg, Servaas 2019, 'The motivational structure of appreciation', in Philosophical Quarterly 69 (276): 445-466

Walton, Kendall 1993, 'How marvelous! Toward a theory of aesthetic value', in The Journal of Aesthetics and Art Criticism 51 (3): 499-510

Whiting, Daniel 2015, 'The glass is half empty: A new argument for pessimism about aesthetic testimony', in The British Journal of Aesthetics 55 (1): 91-107

Zagzebski, Linda 2012, Epistemic Authority (New York: Oxford University Press) 